\title{
Mortality of workers exposed to methylene chloride employed at a plant producing cellulose triacetate film base
}

\author{
John A Tomenson, Susan M Bonner, Colin G Heijne, David G Farrar, \\ Trevor F Cummings
}

ICI Epidemiology Unit, PO Box 7, Brunner House, Winnington, Northwich, Cheshire, CW8 4DJ

J A Tomenson

$S$ M Bonner

ICI Chemicals and Polymers,

Occupational Health PO Box 13, The Heath, Runcorn, Cheshire, WA7 4OF

C G Heijne

D G Farrar

ICI Chemicals and Polymers,

Occupational Health, Wilton Site, PO Box 54, Middlesbrough, Cleveland, TS90 8JA

T F Cummings

Correspondence to: Dr J A Tomenson ICI Epidemiology Unit, PO Box 7, Brunner House, Winnington, Northwich, Cheshire, CW8 4DJ.

Accepted 23 January 1997

\begin{abstract}
Objective-To study mortality among 1785 employees of a factory that produced cellulose triacetate film base at Brantham in the United Kingdom. Also, to investigate patterns of mortality after exposure to methylene chloride; in particular, mortality from liver and biliary tract cancer, lung cancer, pancreatic cancer, and cardiovascular disease.

Subjects and methods-All male employees with a record of employment at the film factory in 1946-88. A total of 1473 subjects worked in jobs that entailed exposure to methylene chloride. The mean duration of exposure was nine years at 19 ppm (eight hour time weighted average). Results-In the cohort, 334 deaths were identified up to 31 December 1994. Mortalities for the cohort were compared with national and local rates and expressed as standardised mortality ratios (SMR). In the subcohort of workers exposed to methylene chloride, substantially reduced mortalities compared with national and local rates were found for all causes, all cancers, and the principal cancer sites of interest. The significantly reduced lung cancer mortalities in exposed workers (SMR 48) seemed to reflect the restrictions on smoking at the workplace. In contrast, mortality from ischaemic heart disease in exposed workers, although lower than national rates (SMR 92), was slightly increased compared with local rates. However, mortality from ischaemic heart disease was lower in active employees (SMR 83) where a direct effect of exposure to methylene chloride should be concentrated. No in service mortality due to ischaemic heart disease was found in workers with the highest cumulative exposure ( $\geqslant 800$ ppm-years).

Conclusions-The study provided no indication that employment at the plant, or exposure to methylene chloride, had adversely affected the mortalities of workers.
\end{abstract}

(Occup Environ Med 1997;54:470-476)

Keywords: methylene chloride; mortality

Methylene chloride (dichloromethane) is a volatile organic solvent with many applications including metal degreasing, aerosol propellant, paint stripping, chemical processing, and the decaffeination of coffee. ${ }^{1}$ The first epidemiological research on the health effects of methylene chloride focused on the fact that it causes a decrease in arterial oxygen content by increasing carboxyhaemoglobin concentrations. Animal bioassays have shown an increased incidence of lung and liver tumours in mice, but not rats, exposed to methylene chloride. ${ }^{2}$ Earlier inhalation studies by Burek et $a l^{\beta}$ in rats and hamsters exposed at similar concentrations had also shown no evidence of lung or liver tumours. Much mechanistic research focusing on the role of reductive metabolism through the glutathione-S-transferase pathway has since taken place to gain understanding of these species differences in response to methylene chloride. ${ }^{4}$

The mortality of three groups of workers exposed to methylene chloride has been studied. The first group of workers were employed in the manufacture of cellulose triacetate photographic film base at a plant in Rochester, New York. $^{5-8}$ The latest report ${ }^{8}$ showed that, compared with both the general population and a group of employed control subjects, there were reduced mortalities for lung and liver cancer and cardiovascular disease. However, there was a non-significant increase in pancreatic cancer (eight observed, 4.2 expected), but no dose related or latency effects were found.

Two other groups of workers have been studied, who worked in plants producing cellulose triacetate fibre. ${ }^{9-12}$ The first group to be studied was a cohort of workers at a plant in Rock Hill, South Carolina. The first study reported no adverse mortality or morbidity experience in these workers. ${ }^{9}$ However, an update of the study ${ }^{10}$ reported a significant excess of deaths from cancer of the biliary passages and liver (four observed, 0.70 expected), although this was essentially an excess of biliary cancer (three observed, 0.15 expected). A second update ${ }^{11}$ reported no additional cases of cancer of the biliary passages and liver, although the number of expected deaths had almost doubled (1.34 expected). Mean exposures to methylene chloride were reported to be substantially higher than for the cohort of photographic film workers.

The other cohort of workers engaged in fibre manufacturing were workers employed at a plant that produced cellulose acetate and triacetate fibres in Cumberland, Maryland. ${ }^{12}$ The 
biliary cancer finding reported in employees at the Rock Hill plant was not corroborated, although there was a small excess of biliary cancer (two observed, 1.4 expected). Cardiovascular mortality in workers exposed to methylene chloride was high compared with state rates, but comparable with local county rates and the level in unexposed workers.

This report describes a cohort mortality study of workers employed at a plant in the United Kingdom, where cellulose triacetate film base was produced between 1950 and 1988. The objectives of the study were to obtain new data on the effect of human exposure to methylene chloride which would help to better characterise health risks and to provide the management and workforce of the plant with information about the health risk experienced at their own plant.

\section{Materials and methods}

STUDY POPULATION AND FOLLOW UP

The design of the investigation was a retrospective cohort study of workers employed at a photographic film base plant in Brantham, United Kingdom. Until 1945, all film base for use in photographic applications in the United Kingdom had to be imported. A plastics company had been producing acetate film at the Brantham site since the early $1930 \mathrm{~s}$, and in 1946 a joint venture was formed with a photographic company to manufacture film base. Large scale production of cellulose triacetate film base began in 1950 and continued until 1988 . However, from the early 1960 s, polyester film was increasingly used at the plant as a photographic film base and production diversified into an expanding range of other coated polyester and acetate films.

Exposure to methylene chloride, which occurred during the production of cellulose triacetate film base and the casting of cellulose diacetate film, was the primary focus of the study. However, the cohort included all male employees who had worked at the site between 1946 and 1988 at any time. Female workers were not included because few had worked in production areas and many had job titles which made exposure difficult to assess. The cohort consisted of 1785 male employees of whom 1473 had worked in jobs that entailed exposure to methylene chloride. The cohort was ascertained from personnel records kept by ICI Bexford and another company operating on the same site. The other company had been part of the original prewar plastics company and had records of employees who had left before 1955 . The cohort has been followed up from 1946 to 1994.

The vital status of the cohort on 31 December 1994 was ascertained from the United Kingdom National Health Service Central Register and the Department of Social Security. The underlying cause of death was coded by the Office of Population Censuses and Surveys according to either the eighth (deaths to 1978) or ninth (deaths from 1979 to 1994) versions of the international classification of diseases (ICD-8 or ICD-9). ${ }^{13}{ }^{14}$ Deaths occur- ring before the ICD-8 (1967) were recoded to the ICD revision in place at the time of death.

\section{EXPOSURE ASSESSMENT}

The study period was divided into four periods (before 1960, 1960-9, 1970-9, 1980-8). However, changes in exposures were mainly gradual, reflecting the numbers of casting machines and their speed of operation. For each of these periods, an estimate of exposure was made for 20 distinct work groups.

More than 2700 results of area monitoring sampling results from 1975 onwards were used to define background exposures in various locations within the plant. Area monitoring data were available before 1975 , but were obtained with a different collection device which has since been shown to give inaccurate results. Background exposure before 1975 was predicted from information about the number of casting machines being operated and their speed of operation (rate of use of methylene chloride). Four casting machines were introduced between 1950 and 1953, and a further four were added between 1958 and 1964. The first seven casting machines to be installed were used to produce cellulose triacetate film base, whereas the eighth produced cellulose diacetate. Six of the machines stopped production during the period 1981-6; the remaining two continued operating until production ended in 1988. The speed of operation of the casting machines increased almost sevenfold between 1950 and the 1980 s.

The background exposure predictions were refined to incorporate assumptions relating to the number of problems experienced with casting machines. Broadly speaking, it was assumed that in the early days of operation, there were fewer machines operating but more teething problems. As the machines became more efficient, they were run better and the problem rate per machine dropped, but this was offset by increases in the speed of operation.

Twenty work groups were created by grouping jobs with similar patterns of work, and hence exposure. For the period 1980-8 estimates of exposure for work groups were derived from personal monitoring data (about 330 sample results collected in the 1980 s). For earlier periods, the estimated exposure of a work group was built up from information about the tasks performed by members of the work group and the locations where they were performed. Task specific exposure factors were derived from the relation between personal and area monitoring data. These factors indicated the level of exposure while performing a task relative to background exposure in that location. Apart from some modifications to reflect process changes, it was assumed that these factors remained constant over time. Thus, for the periods when personal monitoring data were not available, it was possible to estimate the exposure of a worker performing a task by multiplying the estimated background exposure at a location by the task specific exposure factor. The task specific exposure factors ranged from 1 in research or laboratory work to 
3.2 while operating casting machines in one block of the plant. The exposure level of a work group was obtained by summing exposures over tasks, taking into account the time spent in different areas of the plant.

Lifetime cumulative exposure to methylene chloride was calculated by summing the products of mean level of exposure and duration of employment for each job held by a cohort member. The employment histories of $30 \%$ of exposed workers (439) were insufficiently precise to calculate a reliable estimate of cumulative exposure. Most of these workers (420) were labourers and maintenance workers. Some of these workers would have been assigned to process areas and had exposures comparable with operators and cleaners, but others may have spent very little time in exposed areas. The job histories of these workers were not specific enough to differentiate between specific and general workers. The remaining 19 workers had incomplete employment histories.

The non-exposed group consisted of a variety of occupations but all were, by definition, not likely to be exposed either directly or indirectly through their daily work. This does not allow for very low concentrations that may have existed in the general atmosphere around the works. Most of the non-exposed group were office workers in the technical and commercial functions. In comparison, the exposed workers were predominantly manual workers.

\section{STATISTICAL METHODS}

Mortality statistics for England and Wales were used for comparison. The occupational cohort mortality analysis program (OCMAP) was used to sum person-years within categories of age (five year intervals) and calendar period (about five year intervals to conform with changes in the ICD), and to compute standardised mortality ratios (SMRs). ${ }^{15}$ Analyses were performed for the entire cohort and the subcohort of workers who had worked for a minimum of three months. Also, a comparison with local mortalities was made by combining information from two surrounding local districts-Tendring and Samford-compiled for a 10 year period, 1968-78. The mortality data were compiled by the authors of an atlas of mortality. ${ }^{16}$

Duration of employment, cumulative exposure, and latency were treated as time related variables with the values calculated for each person-year under observation. A person was allowed to contribute to more than one stratum in each analysis. Four categories of cumulative exposure to methylene chloride were defined; $0,0-399,400-799$, and $\geqslant 800$ ppm-years. A $\chi^{2}$ test for trend was applied to evaluate the significance of the mortality ratios. ${ }^{17}$ An internally standardised relative risk analysis was also performed with the never exposed group as the internal comparison group. ${ }^{15} \mathrm{~A}$ more qualitative assessment of exposure effect was obtained by performing analyses based on date of first exposure.
Table 1 Vital status on 31 December 1994

\begin{tabular}{llll}
\hline & Exposed & Unexposed & Total \\
\hline Alive & 1139 & 260 & 1399 \\
$\begin{array}{l}\text { Dead } \\
\text { Emigrated or joined armed }\end{array}$ & 287 & 47 & 334 \\
$\quad$ & 43 & 4 & 47 \\
$\begin{array}{l}\text { forces } \\
\text { Total to follow up }\end{array}$ & 4 & 1 & 5 \\
\hline
\end{tabular}

In the case of ischaemic heart disease, it has been proposed that the cardiovascular effects of exposure to carbon monoxide may be acute and reversible. ${ }^{18}$ Therefore, this association was also investigated by restricting the analysis to the period when workers were employed and the first 28 days after the end of employment.

\section{Results}

Table 1 shows the vital status of the cohort on 31 December 1994. A total of 47 workers (2.6\%) had emigrated or joined the armed forces, and a further five workers $(0.3 \%)$ were lost to follow up. Seventy three per cent of exposed workers were less than 35 years of age at the start of follow up as were $65 \%$ of unexposed workers. Ninety four per cent of exposed workers and $88 \%$ of unexposed workers were employed for at least three months. Exposed workers contributed 39759 person-years of follow up and unexposed workers contributed 6652 person-years.

The appendix shows the estimated eight hour time weighted average (8h TWA) exposure to methylene chloride for some of the key work groups, by period. Estimated exposures rose from 1950 up to the late 1970 s reflecting the increasing numbers of casting machines and speed of operation. Mean yearly static monitoring results (based on samples taken weekly) for the casting and dope areas were at their highest in the late $1970 \mathrm{~s}(100-125 \mathrm{ppm})$, but then fell to concentrations of $25-40 \mathrm{ppm}$ during the final years of operation. The 1034 workers for whom it was possible to calculate individual estimates of cumulative exposure to methylene chloride, had been exposed on average for nine years at a concentration of $19 \mathrm{ppm}$ ( $8 \mathrm{~h}$ TWA). It was not possible to calculate the cumulative exposure of individual workers in the unassigned group. However, on average, the group was estimated to have been exposed for 11 years at a concentration of $13 \mathrm{ppm}(8 \mathrm{~h}$ TWA).

Table 2 shows SMRs for the major causes of death and those of initial interest. Results are presented separately for the groups of never exposed workers and exposed workers. Deaths from all causes of death $(P<0.01)$ and all malignant neoplasms $(P<0.01)$ were significantly lower than expected in exposed workers. Deaths from all causes in never exposed workers were also significantly lower than expected $(P<0.05)$ and deaths due to malignant neoplasms were also reduced (SMR 65). Deaths due to the cancers initially of interest - that is, lung, pancreatic, liver, and biliary tract cancers-were all lower than expected in exposed workers. Deaths due to lung cancer were significantly reduced in both exposed 
Table 2 Observed numbers of deaths and SMRst for selected causes of death in the unexposed and exposed cohorts

\begin{tabular}{|c|c|c|c|c|c|c|c|}
\hline \multirow[b]{2}{*}{$I C D-9$} & \multirow[b]{2}{*}{ Cause of death category } & \multicolumn{3}{|c|}{ Never exposed } & \multicolumn{3}{|c|}{ Exposed } \\
\hline & & Obs & $S M R$ & $(95 \% C I)$ & Obs & $S M R$ & $(95 \% C I)$ \\
\hline 001-999 & All causes of death & 47 & $74^{\star}$ & (54 to 99 ) & 287 & $74^{\star \star}$ & (66 to 83 ) \\
\hline $140-208$ & All malignant neoplasms & 11 & 65 & (32 to 116$)$ & 68 & $65^{\star \star}$ & (51 to 82 ) \\
\hline $150-159$ & Digestive system & 5 & 98 & (32 to 228 ) & 20 & $64^{\star}$ & (39 to 100$)$ \\
\hline 151 & Stomach & 1 & 64 & (2 to 358$)$ & 6 & 63 & ( 23 to 137 ) \\
\hline 153 & Colon & 1 & 91 & ( 2 to 506 ) & 6 & 90 & (33 to 196 ) \\
\hline 154 & Rectum & 1 & 130 & (3 to 725 ) & 2 & 44 & ( 5 to 157 ) \\
\hline $155-156$ & Biliary passages and liver & 0 & 0.24 & - & 0 & 1.47 & - \\
\hline 157 & Pancreas & 1 & 138 & (4 to 770 ) & 3 & 68 & (14 to 199$)$ \\
\hline $160-165$ & Respiratory system & 1 & $15^{\star}$ & $(0$ to 84$)$ & 19 & $46^{\star \star}$ & ( 28 to 72 ) \\
\hline 162 & Bronchus, trachea and lung & 1 & $16^{\star}$ & $(0$ to 88$)$ & 19 & $48^{\star \star}$ & (29 to 75 ) \\
\hline 185 & Prostate & 3 & 295 & (61 to 863 ) & 4 & 62 & (17 to 160$)$ \\
\hline 191-192 & Brain and other CNS & 1 & 212 & (5 to 1183 ) & 4 & 145 & (40 to 372$)$ \\
\hline $200-208$ & Lymphatic and haematopoietic tissue & 1 & 86 & (2 to 479 ) & 6 & 85 & (31 to 184$)$ \\
\hline 204-208 & Leukaemia & 1 & 228 & (6 to 1268 ) & 3 & 111 & ( 23 to 326$)$ \\
\hline $430-438$ & Cerebrovascular disease & 6 & 115 & (42 to 250 ) & 16 & $50^{\star \star}$ & ( 29 to 82$)$ \\
\hline $390-398,402,404,410-429$ & All heart disease & 18 & 78 & (46 to 123 ) & 124 & 88 & (74 to 105$)$ \\
\hline $410-414$ & Ischaemic heart disease & 15 & 74 & (41 to 121 ) & 114 & 92 & (76 to 110$)$ \\
\hline $460-519$ & Non-malignant respiratory disease & 6 & 88 & (32 to 191 ) & 24 & $57^{\star \star}$ & (37 to 86 ) \\
\hline $800-999$ & External causes of death & 0 & 3.4 & - & 12 & 58 & (30 to 102 ) \\
\hline
\end{tabular}

${ }^{\star} \mathrm{P}<0.05 ;{ }^{\star \star} \mathrm{P}<0.01 ;$ SMR significantly different from 100 .

$\dagger$ England and Wales mortality rates. Expected number of deaths in italics if $S M R=0$.

$(P<0.01)$ and unexposed $(P<0.05)$ workers, and there were no deaths due to cancer of the biliary passages and liver in the entire cohort. Deaths due to all heart disease and ischaemic heart disease in exposed and never exposed workers were also lower than expected. Results for workers with more than three months of employment were similar and are not presented.

Table 3 provides a more detailed analysis for all causes of death, all malignancies, and causes of death initially of interest. Results are presented for three cumulative dose groups, the group of exposed but unassigned workers, and the never exposed group. There was no evidence of an association between exposure to methylene chloride and all causes of death, all malignancies, and the cancers initially of interest. Some evidence of an association between exposure to methylene chloride and ischaemic heart disease was found, but the test for trend was not significant. Mortality from ischaemic heart disease was similar in unexposed workers and workers exposed to less than $400 \mathrm{ppm}$ years, but higher in the 400-799 ppm-years and $\geqslant 800 \mathrm{ppm}$-years groups. The results of trend analyses were similar when restricted to workers with more than three months employment. The SMR for ischaemic heart disease in unexposed employees with more than three months service was slightly higher than for all unexposed workers (84 $v$ 74) resulting in a slightly higher $\mathrm{P}$ value for the test for trend $(P=0.14)$. The internally standardised analysis gave relative risks that were similar to the ratios of SMRs in table 3 and are not reported in detail.

Table 4 shows observed deaths and SMR for the categories of all causes of death, all malignancies, lung cancer, pancreatic cancer, and ischaemic heart disease by years since first exposure. A small increase in mortality with years since first exposure was apparent for most of the causes shown.

Analyses by date of first exposure performed for different cut off points, showed that mortalities were particularly low in workers who were first exposed after the latest date used for these analyses (1965). The SMR for all causes of death was 54 and that for all cancers was 50 , although there were only 40 deaths in this group. Only two workers had died from lung cancer in this group (SMR 29) and mortality from ischaemic heart disease was also low (SMR 68).

\section{Discussion}

The cohort described in this report, is one of four cohorts which provide most of the information currently available about the

Table 3 Observed deaths and SMRT for selected causes of death by exposure to methylene chloride

\begin{tabular}{|c|c|c|c|c|c|c|c|c|c|c|c|}
\hline \multirow[b]{3}{*}{ Causes of death } & & & \multicolumn{6}{|c|}{ Cumulative exposure to methylene chloride (ppm-y) } & & & \multirow{3}{*}{$\begin{array}{l}\text { P value } \\
\text { for } \\
\text { trend } \neq\end{array}$} \\
\hline & \multicolumn{2}{|c|}{$\begin{array}{l}\text { Never } \\
\text { exposed }\end{array}$} & \multicolumn{2}{|c|}{$\begin{array}{l}<400 \\
(\text { mean }=113)\end{array}$} & \multicolumn{2}{|c|}{$\begin{array}{l}400-799 \\
(\text { mean }=674)\end{array}$} & \multicolumn{2}{|c|}{$\begin{array}{l}\geqslant 800 \\
(\text { mean }=1179)\end{array}$} & \multicolumn{2}{|c|}{$\begin{array}{l}\text { Unassigned } \\
\text { exposure }\end{array}$} & \\
\hline & Obs & $S M R$ & Obs & $S M R$ & Obs & $S M R$ & Obs & $S M R$ & Obs & $S M R$ & \\
\hline All deaths & 47 & $74^{\star}$ & 123 & $66^{\star \star}$ & 31 & 85 & 17 & 73 & 116 & $83^{\star}$ & 0.49 \\
\hline All malignant neoplasms & 11 & 65 & 27 & $54^{\star \star}$ & 7 & 70 & 3 & 43 & 31 & 83 & 0.86 \\
\hline Pancreatic cancer & 1 & 138 & 1 & 47 & 0 & 0.42 & 0 & 0.30 & 2 & 127 & 0.43 \\
\hline $\begin{array}{l}\text { Cancer of the } \\
\text { bronchus, trachea }\end{array}$ & 1 & $16 \star$ & 6 & $32 \star \star$ & 2 & - & 1 & 37 & 10 & 68 & 0.53 \\
\hline $\begin{array}{l}\text { All cancers except } \\
\text { bronchus, trachea, }\end{array}$ & 1 & 10 & 0 & J2 & 2 & 政 & 1 & 47 & & & \\
\hline and lung & 10 & 94 & 21 & $67^{\star}$ & 5 & 82 & 2 & 47 & 21 & 92 & 0.61 \\
\hline Ischaemic heart disease & 15 & 74 & 47 & 79 & 13 & 106 & 10 & 122 & 44 & 99 & 0.11 \\
\hline
\end{tabular}

$\star \mathrm{P}<0.05 ;{ }^{\star \star} \mathrm{P}<0.01 ; \mathrm{SMR}$ significantly different from 100

+ England and Wales mortality rates. Expected number of deaths given in italics if $S M R=0$.

‡ Excluding unassigned exposure group. 
Table 4 Observed numbers of deaths and SMRt in exposed workers for selected causes by years since first exposure

\begin{tabular}{|c|c|c|c|c|c|c|}
\hline \multirow[b]{3}{*}{ Causes of death } & \multicolumn{6}{|c|}{ Years since first exposure } \\
\hline & \multicolumn{2}{|c|}{$<20$} & \multicolumn{2}{|c|}{$20-30$} & \multicolumn{2}{|c|}{$>30$} \\
\hline & $O b s$ & $S M R$ & Obs & $S M R$ & Obs & $S M I$ \\
\hline All causes & 81 & $62^{\star \star}$ & 98 & 83 & 108 & $78^{\star}$ \\
\hline All malignant $\mathrm{r}$ & 18 & $53^{\star \star}$ & 20 & $61^{\star}$ & 30 & 7 \\
\hline Pancreatic cancer & 0 & 1.39 & 2 & 139 & 1 & 63 \\
\hline $\begin{array}{l}\text { Cancer of bronchus, } \\
\text { trachea, and lung } \\
\text { All cancers except }\end{array}$ & 5 & $38^{\star}$ & 5 & $39^{\star}$ & 9 & 65 \\
\hline $\begin{array}{l}\text { bronchus, trachea, } \\
\text { and lung }\end{array}$ & 13 & 63 & 15 & 75 & 21 & 86 \\
\hline Ischaemic heart disease & 28 & 73 & 47 & 116 & 39 & 86 \\
\hline
\end{tabular}

$\star P<0.05 ;{ }^{\star} \star P<0.01 ;$ SMR significantly different from 100 $\dagger$ England and Wales mortality rates. Expected number of deaths given in italics if $S M R=0$.

human health effects of methylene chloride. This cohort, along with a second ${ }^{8}$ consists of workers exposed to methylene chloride during the manufacture of cellulose triacetate film base. The other two groups of workers that have been studied incurred exposure to methylene chloride in the production of cellulose triacetate fibres. ${ }^{112}$ The mean exposure of workers in the present investigation, $19 \mathrm{ppm}$, was similar to that in the other cohort of photographic workers, $26 \mathrm{ppm}$, although the mean duration of exposure of workers was shorter (nine $v 23$ years). However, levels of exposure in the two cohorts of fibre workers were much higher. One study of fibre workers reported median exposures for three groups of workers of $140 \mathrm{ppm}, 280 \mathrm{ppm}$, and $475 \mathrm{ppm}$ ( $8 \mathrm{~h}$ TWA ${ }^{11}$ and the other study reported the mortality experience of one group of workers exposed to concentrations of $350-700 \mathrm{ppm}$ and a second group exposed to concentrations of $50-100 \mathrm{ppm}$ ( $8 \mathrm{~h}$ TWA). ${ }^{12}$ Three of the cohorts are of similar size, but one of the cohorts of fibre workers ${ }^{12}$ is about three times larger. However, the large cohort has been followed up for the shortest period (20 years). Both cohorts of photographic film workers include only male subjects, but a large proportion of the fibre workers were women.

The current study group, like the other three, have experienced reduced overall mortality and reduced mortality from cancer. Because lung cancers form such a high proportion of cancer deaths, low mortality due to cancer might have been expected as workers were not allowed to smoke at their workstation. All four studies have reported lower mortality than expected for lung cancer, but this finding was especially true for exposed workers in this study (SMR 48). However, mortality from other types of cancer apart from lung cancer was also low (SMR 75). Thus, the increased incidence of lung cancer seen in the mouse bioassay is not corroborated by the epidemiology studies, although confounding by smoking may have limited the ability of these studies to detect an effect of exposure to methylene chloride on risk of lung cancer. The current investigation also provided no evidence of an increased risk of liver cancer as seen in the mouse bioassay, nor support for the excess of biliary cancer reported in one group of cellulose triacetate fibre workers. ${ }^{11}$ However, the excess of biliary cancer was not replicated in another highly exposed group of fibre workers $^{12}$ nor the other cohort of photographic film workers. ${ }^{8}$

A small excess of pancreatic cancer was reported in the earlier study of photographic film workers (eight observed and 4.2 expected). An excess of pancreatic cancer (three observed and 0.9 expected) was also found in a group of 226 men employed in production of chlorinated methanes. ${ }^{19}$ However, all had been employed for short periods and information on the exposure of the cohort was not provided. The present study and the two studies of highly exposed fibre production workers ${ }^{11}{ }^{12}$ provide no support for an association between pancreatic cancer and exposure to methylene chloride.

Heineman et $a l^{20}$ reported an association between astrocytic brain cancer and exposure to methylene chloride in a case-control study of astrocytic brain cancer and occupational exposure to chlorinated aliphatic hydrocarbons. Heineman $e t a l^{20}$ reported that the risk of astrocytic brain cancer increased with probability and average intensity of exposure, and with duration of employment in jobs considered exposed to methylene chloride, and the trends could not be explained by exposures to the other solvents studied. There was a small excess of brain tumours in exposed workers in this cohort (four observed and 2.8 expected), but two of these workers had minimal exposure to methylene chloride. One employee had been a laboratory assistant for four years, the other was involved in estimation work in the engineering department. Another worker was an electrician from the unassigned exposure group. This job title was insufficiently precise to identify the areas worked. It was estimated that the mean exposure of this worker, who was employed for 21 years, was unlikely to have exceeded $15 \mathrm{ppm}$ (8h TWA).The cumulative exposure of the other worker who died of brain cancer was estimated to be 572 ppm-years (casting machine operator for 23 years). Hence, the small excess of brain cancer in this study did not seem to be associated with exposure to methylene chloride. No support for an association between methylene chloride and brain cancer was provided by the other three retrospective cohort studies. ${ }^{811} 12$ These studies provided more relevant information than the case-control study ${ }^{20}$ which relied on information obtained from the next of kin.

Mortality due to ischaemic heart disease was slightly higher in exposed workers (SMR 92), than in never exposed workers (SMR 74). When local mortalities were used for comparison, the SMR of exposed workers increased to 104 (95\% CI; 86 to 125$)$. Lower mortalities from ischaemic heart disease in exposed workers might have been expected because of the restrictions on smoking at the plant. However, the plant is situated in a rural area with low smoking rates which are reflected in the SMR for lung cancer of 77 in the local community. A suggestion of a trend in ischaemic heart disease 
with cumulative exposure was also found, although this was not significant.

A role for methylene chloride in the induction of ischaemic heart disease is plausible because methylene chloride is metabolised to carbon monoxide and induces the formation of carboxyhaemoglobin. Stern et $a l^{1}$ reported an increased risk of ischaemic heart disease in tunnel workers historically exposed to carbon monoxide concentrations averaging about 50 ppm. However, the increased risk declined after end of exposure with much of the risk dissipating after five years. This pattern mirrors that of cigarette smoking and cardiovascular mortality and suggests that a direct effect of methylene chloride on ischaemic heart disease and cardiovascular mortality would be concentrated in active employees. When the analysis was restricted to active employees (including any deaths that occurred within one month of the end of employment), the SMR for ischaemic heart disease decreased to 83 , and no in service deaths due to ischaemic heart disease occurred in workers in the highest cumulative exposure group ( $\geqslant 800 \mathrm{ppm}$-years). This does not rule out the possibility that exposure to methylene chloride increases the risk of ischaemic heart disease, as some reduction in SMR would be anticipated because the healthy worker effect would be expected to be stronger for this period of follow up. The group of never exposed workers was too small to perform a meaningful comparison analysis as only one employee in this group died from ischaemic heart disease while still employed (3.0 expected deaths).

The results from the other three cohorts of workers exposed to methylene chloride have been contradictory for mortality from cardiovascular disease. Mortality from ischaemic heart disease was higher than expected in one cohort when compared with state mortalities, but comparable with the local mortalities for the county in which the plant was situated. ${ }^{12}$ Three investigations ${ }^{922}$ have studied the cardiovascular health of some of the workers in the present cohort and that studied by Rothman et al. ${ }^{11}$ None of these studies showed any evidence of long term damage that could be attributed to exposure to methylene chloride.

Analyses by latency provided evidence that mortality from all cancers and lung cancer increased slightly with time since first exposure (table 4). This might have been expected for conditions such as ischaemic heart disease for which the healthy worker effect would have been expected to decline with years since first exposure. However, there were no other indications from other analyses that this effect was related to exposure to methylene chloride.

A potential weakness of the current study was the lack of personal monitoring data before 1980 and valid area monitoring data before 1975. However, good historical information on the casting machines and working conditions was available. The exposure estimation was considered to be least robust for the period before 1965 when casting machines were being introduced. However, the analyses by period did not provide any evidence of increased mortality in workers who were first exposed before 1965 . Information was also available on incidents where workers were affected by methylene chloride vapours. The number of incidents was small, but the information fitted with the pattern of exposure estimated for jobs and periods.

Another study weakness was the inability to include $30 \%$ of exposed workers (the unassigned exposure group) in the dose response analyses. Overall, this group was estimated to have experienced lower mean exposures than the other exposed workers (13 ppm $v 19 \mathrm{ppm}$ TWA). Their mortality results, and distribution of person-years of follow up, were similar to those of the group of workers for whom it was possible to calculate cumulative exposure.

In conclusion, this study provides no evidence of increased mortality related to exposure to methylene chloride. The only suggestion of increased mortality was the increased SMR for ischaemic heart disease in the two highest cumulative exposure groups. A role for methylene chloride in the induction of ischaemic heart disease is plausible, but there was no evidence that such an effect was occurring while workers were exposed to methylene chloride-that is, when the effect would be expected to be strongest. However, although this study, like others, did not provide any compelling evidence of an increased risk of cardiovascular disease, the restrictions on smoking at workstations may have limited the ability of all of these studies to detect an exposure related effect on mortality from cardiovascular disease. There was no evidence of any increased carcinogenic risk in this population. This was not simply due to a reduced incidence of lung cancer resulting from a low prevalence of smoking in the cohort. Mortality from cancers other than lung cancer was significantly less than expected, mirroring the pattern found in the other three cohorts of photographic film workers and fibre workers (SMR range 69-87).

We thank Barbara Eyres, Robert Beckerleg, and Alwyn Clarkson for help with data collection, two anonymous referees for their constructive comments on an earlier draft and Angela Benson for help in preparation of the manuscript.

1 United States Environmental Protection Agency. Health assessment document for dichloromethane (methylene chloride). Protetion Agency, 1985. (Final report PB85-191559.)

2 National Toxicology Program. NTP technical report on the toxicology and carcinogenesis studies of dichloromethane in coxicology and carcinogenesis studies of dichloromethane in F344/N rats and B6C3F mice (inhalation studies) Cincinnati: United States Department of Health and HTP-TR 306.)

3 Burek JD, Nitschke KD, Bell TJ, et al. Methylene chloride: a two-year inhalation toxicity and oncogenicity study in rats and hamsters. Fundam Appl Toxicol 1984;4:30-47.

4 European Chemical Industry Ecology and Toxicology Centre. The assessment of carcinogenic hazard for human being exposed to methylene chloride. Brussels: ECIETC, 1987. (Technical report No 26.)

5 Friedlander BR, Hearne T, Hall S. Epidemiologic investigation of employees chronically exposed to methylen chloride: mortality analysis. $\mathcal{F}$ Occup Med 1978;20:657-66.

6 Hearne FT, Friedlander BR. Follow-up of methylene chloride study [letter]. F Occup Med 1981;23:660

7 Hearne FT, Grose F, Pifer JW, Friedlander BR, Raleigh RI Methylene chloride mortality study: dose-response characterisation and animal model comparison. $\exists$ Occup $M$ ed 1987;29:217-28. 
8 Hearne FT, Pifer JW, Grose F. Absence of adverse mortality effects in workers exposed to methylene chloride: an update. $\mathcal{F}$ Occup Med 1990;32:234-40.

9 Ott MG, Skory LK, Holder BB, Bronson JH, Williams PR. Health evaluation of employees occupationally exposed to methylene chloride. Scand $\mathcal{F}$ Work Environ Health 1983;9:138.

10 Lanes SF, Cohen A, Rothman KJ, Dreyer NA, Soden KJ Mortality of cellulose fiber production workers. Scand $\mathcal{f}$ Work Environ Health 1990;16:247-51.

11 Rothman KJ, Dreyer NA, Soden KJ. Mortality update of cellulose fiber production workers. Scand $\mathcal{f}$ Work Environ Health 1993;19:426-8.

12 Gibbs GW,Amsel J, Soden K. A cohort mortality study of cellulose triacetate fiber workers exposed to methylene chloride. F Occup Environ Med 1996;38:693-7.

13 World Health Organisation. Manual of the international classification of diseases, injuries and causes of death, 8th rev. Geneva: WHO, 1967.

14 World Health Organisation. Manual of the international classification of diseases, injuries and causes of death, 9 th rev. Geneva: WHO, 1977.

15 Marsh GM, Preininger M. OCMAP: a user-oriented occupational cohort mortality analysis program. American Statistician 1980;34:245.

16 Gardner MJ, Winter PD, Barker DJP. Atlas of mortality from selected diseases in England and Wales 1968-78. Chichester: John Wiley, 1984.

17 Hakulinen T. A Mantel-Haenszel statistic for testing the association between polychotomous exposure and a rare outcome. Am f Epidemiol 1981;113:192-6.

18 Kristensen TS. Cardiovascular diseases and the work environment: a critical review of the epidemiologic literature on chemical factors. Scand $\mathcal{F}$ Work Environ Health 1989;15:245-64.
19 Ott MG, Carlo GL, Steinberg S, Bond GG. Mortality among employees engaged in chemical manufacturing and related activities. Am $\Im$ Epidemiol 1985;122:311-22.

20 Heineman EF, Cocco P, Gomez MR, Dosemeci M, Stewart ( PA, Hayes RB, et al. Occupational exposure to chlorinated alphatic hydrocarbons and risk of astrocytic brain cancer. Am $\mathcal{F}$ Ind Med 1994,26:155-69.

21 Stern FB, Halperin WE, Hornung RW, Ringenburg VL, McCammon CS. Heart disease mortality among bridge and tunnel officers exposed to carbon monoxide. Am $\mathcal{F} E p i$ demiol 1988;128:1276-88.

22 Soden KJ. An evaluation of chronic methylene chloride exposure. f Occup Med 1993;35:282-6.

23 Cherry N, Venables H, Waldron HA, Wells GG. Some observations on workers exposed to methylene chloride. $B$ f Ind Med 1981;38:351-5.

Appendix: Estimated exposures (8h TWA, ppm) for selected work groups

\begin{tabular}{|c|c|c|c|c|}
\hline \multirow[b]{2}{*}{ Work group } & \multicolumn{4}{|l|}{ Period } \\
\hline & $\begin{array}{l}\text { Before } \\
1960\end{array}$ & $1960-9$ & $1970-9$ & $1980-8$ \\
\hline $\begin{array}{l}\text { Dope section } \\
\text { Operator (D) }\end{array}$ & 20 & 50 & 165 & 73 \\
\hline $\begin{array}{l}\text { block) } \\
\text { Operator (B/C }\end{array}$ & - & 127 & 127 & 88 \\
\hline blocks) & 16 & 24 & 54 & 32 \\
\hline Solvent recovery & 6 & 16 & 53 & 27 \\
\hline Cleaning & 7 & 22 & 46 & 25 \\
\hline Subwash operator & 2 & 6 & 19 & 10 \\
\hline Laboratory & 4 & 6 & 10 & 7 \\
\hline
\end{tabular}

\section{Rejected manuscripts}

From February 1994, authors whose submitted articles are rejected will be advised of the decision and one copy of the article, together with any reviewer's comments, will be returned to them. The fournal will destroy remaining copies of the article but correspondence and reviewers' comments will be kept. 